\title{
Olsalazine in active ulcerative colitis
}

\author{
W S SELBY, G D BARR, A IRELAND, C H MASON, D P JEWELL
}

\begin{abstract}
Olsalazine (azodisalicylate) is a new drug in which two molecules of 5-aminosalicylic acid are linked by an azo bond. Its role in the treatment of mildly active, distal ulcerative colitis was investigated. Sixty patients were randomly allocated to receive olsalazine $1 \mathrm{~g}$ or a placebo as a retention enema nightly for two weeks. Clinical improvement was seen in $19(66 \%)$ and sigmoidoscopic improvement in $17(59 \%)$ of the 29 patients receiving olsalazine compared with $12(43 \%)$ and $11(39 \%)$, respectively, of the 28 in the control group. These differences were not significant. In a second trial 40 patients were randomised to receive oral olsalazine $2 \mathrm{~g}$ daily or a placebo capsule for two weeks. Significant clinical and sigmoidoscopic improvement was seen in the patients receiving oral olsalazine compared with the patients receiving placebo capsules.
\end{abstract}

Oral olsalazine may be valuable in the treatment of mildly active ulcerative colitis. Its role in maintaining remission is yet to be determined.

\section{Introduction}

Sulphasalazine is effective as maintenance treatment for patients with ulcerative colitis, apparently over many years. ${ }^{1}$ It cannot be tolerated by $10-15 \%$ of patients, ${ }^{2}$ however, and many of its side effects can be attributed to its sulphapyridine content. ${ }^{3}{ }^{4}$ Considerable evidence exists suggesting that for treating mildly active disease 5 -aminosalicylic acid is the active substance. ${ }^{5.7}$ Olsalazine (Dipentum; azodisalicylate) consists of two molecules of 5 aminosalicylic acid linked with an azo bond. It has pharmacokinetic

Gastroenterology Unit, Radcliffe Infirmary, Oxford 0X2 6HE

W S SELBY, MB, FRACP, research fellow

G D BARR, MB, FRACP, research fellow

A IRELAND, MB, MRCP, research fellow

C H MASON, BM, BCH, clinical lecturer in pathology

D P JEWELL, DPHIL, FRCP, consultant physician

Correspondence to: Dr Jewell. properties similar to those of sulphasalazine ${ }^{8}$ and when it is given orally high concentrations of 5-aminosalicylic acid are found in faecal water. ${ }^{9}$ Preliminary observations in patients with ulcerative colitis suggested that when given as a retention enema it was effective in treating active disease. ${ }^{10}$

We report two trials of olsalazine in patients with active ulcerative colitis. The first compared olsalazine given as an enema with a placebo preparation. The second compared oral olsalazine with placebo capsules.

\section{Patients and methods}

\section{ENEMA TRIAL}

Sixty patients ( 34 men, 26 women) with a mild attack of ulcerative colitis (defined according to the criteria of Truelove and Witts ${ }^{11}$ ) entered the study. All patients had left sided disease, as determined radiographically. Table I lists the details of the patients, including the duration of disease and the number of patients taking sulphasalazine on entry to the study. Those who entered the study during a relapse and who were already receiving sulphasalazine continued to take this drug in the same dosage throughout the trial. Patients who were receiving corticosteroids (systemically or topically) or immunosuppressive drugs were excluded. Patients were randomly allocated (randomisation being restricted in blocks of four) to receive either an enema containing olsalazine or a placebo enema nightly for two weeks. The active enema contained $2 \mathrm{~g}$ olsalazine, $0.1 \mathrm{~g}$ methyl hydroxybenzoate, and $0.03 \mathrm{~g}$ propyl hydroxybenzoate in distilled water to $100 \mathrm{ml}$, and the placebo enema contained $0.001 \mathrm{~g}$ erythrosine, $0.025 \mathrm{~g}$ riboflavine, $0.1 \mathrm{~g}$ methyl hydroxybenzoate, and $0.03 \mathrm{~g}$ propyl hydroxybenzoate in distilled water to $100 \mathrm{ml}$; both enemas looked identical and were dispensed by the hospital pharmacist. Both active and placebo enemas were contained in yellow plastic bottles equipped with a nozzle set and a one way valve.

The study was approved by the hospital ethical committee, and informed consent was obtained from each patient.

Patients were assessed on entry to the study and after the two week trial. The number and consistency of stools and the presence of blood, mucus, and abdominal pain were recorded. Improvement in any of these symptoms was judged to represent a positive response. Any patient whose clinical state deteriorated during the trial was regarded as a failure and withdrawn from the trial. Sigmoidoscopy with rectal biopsy was performed on entry and after two weeks. Sigmoidoscopic and histological appearances were graded as described by Dick et al and Truelove and Richards, respectively. ${ }^{12}{ }^{13}$ The pathologist did not know which treatment each patient was receiving.

Complete histological data were available for only 25 of the patients in the group given active treatment and 26 of those given placebo treatment who completed the trial. Blood was taken for routine haematological and biochemical analysis. 


\section{ORAL TRIAL}

Forty patients entered the trial of oral treatment (table I). Criteria for admission, the design of the trial, and assessment were the same as in the enema trial. Patients who were taking oral sulphasalazine stopped doing so on entry to the trial.

Patients received either $0.5 \mathrm{~g}$ olsalazine or one placebo capsule four times a day. Each active capsule contained $250 \mathrm{mg}$ olsalazine and each placebo capsule $248.15 \mathrm{mg}$ potato starch, $1.75 \mathrm{mg}$ riboflavine, and $0.1 \mathrm{mg}$ indigo carmine. The substances were packed into yellow gelatin snap fit capsules.

\section{STATISTICAL ANALYSIS}

Both trials were analysed as $2 \times 3$ contingency tables using a $\chi^{2}$ test.

\section{Results}

\section{ENEMA TRIAL}

Table I shows that both groups were evenly matched for age, sex, duration of history, and previous treatment with sulphasalazine. Two patients, both receiving placebo enemas, failed to present for the second visit, and one patient was withdrawn because of rectal pain induced by the olsalazine enema. first attack of ulcerative colitis. These numbers were too small for analysis, $\underline{\underline{T}}$ but the responses of these patients were similar to the overall results.

Apart from the rectal pain in one patient, no adverse reactions to olsalazine $\stackrel{8}{\Omega}$ enemas occurred. There were no changes in blood count, results of liver $c$ function tests, or concentrations of electrolytes, urea, and creatinine that $\widehat{\widehat{C}}$ could have been attributed to the drug.

\section{ORAL TRIAL}

The two groups were reasonably matched (table I). No patients dropped $\Rightarrow$ out, and all were available for analysis. Complete histological data were not $\stackrel{\mathcal{O}}{ }$ available for one patient in the group receiving olsalazine and two in the group receiving placebo.

Patients receiving oral olsalazine had a significantly better response $\frac{\bar{\sigma}}{\bar{\sigma}}$ $(\mathrm{p}<0.02)$ than patients treated with placebo capsules (table III). Thirteen of $\vec{\Phi}$ the 20 patients receiving oral olsalazine improved compared with eight of the 20 receiving placebo; but nine patients receiving placebo deteriorated compared with only one receiving olsalazine. Table III shows that in terms of $\overrightarrow{0}$ sigmoidoscopic response the group receiving olsalazine fared better than the group receiving placebo $(p<0.05)$. Only three patients in the group $\vec{\omega}$ receiving olsalazine and one in the group receiving placebo showed $O$ histological improvement.

No differences were seen in patients who had not been treated before compared with those who had relapsed while taking sulphasalazine. Six $\mathbb{N}$ patients entered the trial during their first attack: three received olsalazine.

TABLE 1-Details of patients

\begin{tabular}{|c|c|c|c|c|}
\hline & \multicolumn{2}{|c|}{ Enema trial } & \multicolumn{2}{|c|}{ Capsule trial } \\
\hline & $\begin{array}{l}\text { Patients receiving olsalazine } \\
\qquad(\mathrm{n}=30)\end{array}$ & $\begin{array}{l}\text { Patients receiving placebo } \\
\qquad(\mathbf{n}=30)\end{array}$ & $\begin{array}{l}\text { Patients receiving olsalazine } \\
\qquad(\mathrm{n}=20)\end{array}$ & $\begin{array}{l}\text { Patients receiving placebo } \\
\qquad(\mathrm{n}=20)\end{array}$ \\
\hline No of men & 19 & 15 & 12 & 6 \\
\hline No of women & 11 & 15 & 8 & 14 \\
\hline Mean age (range) (years) & $42(18-75)$ & $43(19-72)$ & $42(19-67)$ & $50(15-81)$ \\
\hline \multirow{2}{*}{$\begin{array}{l}\text { No of patients suffering first attack of } \\
\text { ulcerative colitis }\end{array}$} & & & & \\
\hline & 3 & 5 & 4 & 3 \\
\hline \multirow{2}{*}{$\begin{array}{l}\text { No of patients suffering relapse } \\
\text { Mean duration of history (years) } \\
\text { (range) }\end{array}$} & 27 & 25 & 16 & 17 \\
\hline & 8.4 ( 6 weeks- 18 yrs $)$ & 8.8 ( 3 weeks- 35 yrs $)$ & $6.9(4$ weeks- 21 yrs $)$ & $8 \cdot 1$ ( 6 weeks- 16 yrs $)$ \\
\hline \multirow{2}{*}{$\begin{array}{l}\text { No of patients already taking } \\
\text { sulphasalazine }\end{array}$} & & & & \\
\hline & 20 & 22 & 13 & 12 \\
\hline
\end{tabular}

Table II shows the clinical and sigmoidoscopic results. Nineteen of the 29 patients receiving olsalazine enemas improved clinically, and 17 of these improved sigmoidoscopically. These responses were not significantly different from those seen in the 28 patients receiving the placebo enema, of whom 12 improved clinically and 11 sigmoidoscopically. Similarly, there was no significant difference in histological responses between the two groups, with 10 of 25 patients receiving olsalazine showing improvement compared with seven of 26 receiving placebo. Three patients in each group showed increased inflammation on histological examination, although their clinical and sigmoidoscopic appearances did not deteriorate.

The clinical, sigmoidoscopic, and histological responses in patients taking oral sulphasalazine were analysed separately. No differences were observed in the response to olsalazine between those patients who were receiving oral sulphasalazine at entry to the trial and those who were not. Five patients receiving placebo and three receiving olsalazine enemas were suffering their

TABLE II-Responses to olsalazine and placebo enemas

\begin{tabular}{lccc}
\hline & $\begin{array}{c}\text { Olsalazine enema } \\
(\mathrm{n}=29)\end{array}$ & $\begin{array}{c}\text { Placebo enema } \\
(\mathrm{n}=28)\end{array}$ & $\begin{array}{c}\text { Total } \\
(\mathrm{n}=57)\end{array}$ \\
\hline Clinical response: & 19 & 12 & 31 \\
$\quad$ Improved & 9 & 14 & 23 \\
$\quad \begin{array}{l}\text { Unchanged } \\
\text { Worse }\end{array}$ & 1 & 2 & 3 \\
$\quad \begin{array}{l}\text { Sigmoidoscopic response: } \\
\quad \text { Improved }\end{array}$ & 17 & 11 & 28 \\
$\quad \begin{array}{l}\text { Unchanged } \\
\text { Worse }\end{array}$ & 11 & 15 & 26 \\
& 1 & 2 & 3 \\
\hline
\end{tabular}

For clinical response $\chi^{2}=2 \cdot 98$, NS

For sigmoidoscopic response $\chi^{2}=2 \cdot 217$, NS.
TABLE III-Responses to oral olsalazine and placebo capsules

\begin{tabular}{lccc}
\hline & $\begin{array}{c}\text { Group receiving } \\
\text { olsalazine } \\
(\mathrm{n}=\mathbf{2 0})\end{array}$ & $\begin{array}{c}\text { Group receiving } \\
\text { placebo } \\
(\mathrm{n}=20)\end{array}$ & $\begin{array}{c}\text { Total } \\
(\mathrm{n}=\mathbf{4 0})\end{array}$ \\
\hline $\begin{array}{l}\text { Clinical response: } \\
\text { Improved }\end{array}$ & 13 & 8 & 21 \\
$\quad \begin{array}{l}\text { Unchanged } \\
\text { Worse }\end{array}$ & 6 & 3 & 10 \\
$\begin{array}{l}\text { Sigmoidoscopic response: } \\
\quad \text { Improved } \\
\quad \text { Unchanged } \\
\text { Worse }\end{array}$ & 1 & 9 & 16 \\
\end{tabular}

For clinical response $\chi^{2}=8 \cdot 56, \mathrm{p}<0.02$.

For sigmoidoscopic response $\chi^{2}=6.39, p<0.05$

and three placebo capsules. Analysis of such small numbers contributes $\mathbb{N}$ little, but their responses were similar.

Two patients taking olsalazine complained of mild headache and one of $\sigma$ lightheadedness. Two patients had increased diarrhoea; in one this was associated with more active disease, but the other showed no deterioration in sigmoidoscopic or histological appearances. One of the patients receiving $\mathbb{D}$ placebo capsules complained of nausea, but there were no other adverse reactions. No haematological or biochemical changes that might have been $\frac{\tau}{T}$ caused by olsalazine occurred.

\section{Discussion}

We found that patients with mild distal ulcerative colitiso responded significantly better to oral olsalazine than to placebo 
capsules. Although the proportion of patients receiving oral olsalazine ( $2 \mathrm{~g}$ daily) who had a good clinical response was greater than the proportion receiving placebo who did so, the most striking difference between the two groups was the clinical deterioration seen in those receiving the placebo. Greater clinical benefit might therefore be seen with longer periods of treatment or higher doses of olsalazine.

In both trials the response of those receiving placebo was high, of the order of $40 \%$. Some studies have yielded similarly high rates of response to placebo, ${ }^{12-16}$ although others have reported rates of 20 $30 \% .^{6}{ }^{17}$

The failure to obtain a significant response to olsalazine enemas was surprising. Enemas of $\mathrm{N}$-acetyl 5 -aminosalicylic acid or 4aminosalicylic acid, given according to a similar protocol, have resulted in significant rates of response. ${ }^{14}{ }^{17}$ It is conceivable that olsalazine was not adequately split to deliver two molecules of 5aminosalicylic acid when administered as an enema. No data are available on this point, but as all patients in this trial were able to retain the enema this seems an unlikely explanation.

Sulphasalazine itself is not a powerful drug for the treatment of active ulcerative colitis and is considerably less effective than corticosteroids.$^{18}$ Its principal use is in maintaining remission, and it is for this that olsalazine has been developed. Trials comparing olsalazine with sulphasalazine in the long term are now in progress.

WSS, GDB, and AI were in receipt of fellowships in gastroenterology from the University of Oxford. We thank Dr S C Truelove for his helpful advice and criticism and Pharmacia for support and for supplying materials.

\section{References}

1 Dissanayake AS, Truelove SC. A controlled therapeutic trial of long-term maintenance treatment of ulcerative colitis with sulphasalazine (Salazopyrin). Gut 1973;14:923-6.

2 Taffet SL, Das KM. Sulphasalazine—adverse effects and desensitization. Dig Dis Sci 1983;28: 833-42.

3 Das KM, Eastwood MA, McManus JPA, Sircus W. Adverse reactions during salicylazosulphapyridine therapy and the relation with drug metabolism and acetylate phenotype. $N \mathrm{Engl}$ f Med 1973;289:491-5

4 O'Morain C, Smethurst P, Dore CJ, Levi AJ. Reversible male infertility due to sulphasalazine in studies in man and rat. Gut 1984;25:1078-84.

5 Khan AKA, Piris J, Truelove SC. An experiment to determine the active moiety of sulphasalazine. Lancet 1977;ii:892-5.

6 Van Hees PAM, Bakker JH, Van Tongeren JHM. Effect of sulphapyridine, 5-aminosalicylic acid, and placebo in patients with idiopathic proctitis: a study to determine the active therapeutic moiety of sulphasalazine. Gut 1980;21:632-5.

7 Klotz U, Maker K, Fischer C, Heinkel K. Therapeutic efficacy of sulphasalazine and its metabolites in patients with ulcerative colitis and Crohn's disease. N Engl f Med 1980;303:1499502 .

8 Willoughby CP, Aronson JK, Agback H, Bodin NO, Truelove SC. Distribution and metabolism in healthy volunteers of disodium azodisalicylate, a potential therapeutic agent for ulcerative colitis. Gut 1982;23: 1081-7.

9 Lauritsen K, Hansen J, Ryde M, Rask-Madsen J. Colonic azodisalicylate metabolism determined by in vivo dialysis in healthy volunteers and patients with ulcerative colitis. Gastroenterology 1984;86: $1496-500$

10 Jewell DP, Truelove SC. Disodium azodisalicylate in ulcerative colitis. Lancet 1981;ii:1168-9.

11 Truelove SC, Witts LJ. Cortisone in ulcerative colitis. Br Med f 1955;ii: 1041-8.

12 Dick AP, Gravson MJ, Carpenter RG, Petrie A. Controlled trial of sulphasalazine in the treatment of ulcerative colitis. Gut 1984;5:437-42.

13 Truelove SC, Richards WCD. Biopsy studies in ulcerative colitis. Br Med 7 1956;i: 1315-8.

14 Selby WS, Bennett MK, Jewell DP. Topical treatment of distal ulcerative colitis with 4 Selby WS, Bennett MK, Jewell DP. Topical treatmen
aminosalicylic acid enemas. Digestion 1984;29:231-4.

15 Baron JH, Connell AM, Lennard-Jones JE, Jones FA. Sulphasalazine and salicylazosulphadimidine in ulcerative colitis. Lancet 1962;i: 1094-6.

16 Binder V, Halskov S, Hvidberg E, et al. A controlled study of 5-acet-aminosalicylic acid (5-AcASA) as enema in ulcerative colitis. Scand f Gastroenterol 1981;16:1122.

17 Willoughby CP, Piris, J, Truelove SC. The effect of topical $N$-acetyl-5-aminosalicylic acid in ulcerative colitis. Scand $\mathcal{F}$ Gastroenterol 1980;15:715-9.

18 Truelove SC, Watkinson G, Draper G. Comparison of corticosteroid and sulphasalazine therapy in ulcerative colitis. Br Med f 1962;ii:1708-11.

(Accepted 5 September 1985)

\title{
Possible mechanism for mianserin induced neutropenia associated with saturable elimination kinetics
}

\author{
J L O'DONNELL, J R SHARMAN, E J BEGG, B M COLLS, P W MOLLER
}

\begin{abstract}
Two cases of mianserin induced neutropenia associated with prolonged elimination of the drug were studied. In each case the pharmacokinetic profile suggested saturable elimination kinetics, and the temporal relation of mianserin concentrations and the neutrophil count suggested a direct toxic effect of mianserin on the bone marrow.

Until further studies are carried out the plasma mianserin concentration and neutrophil count should be measured in any patient who develops an infection while taking this drug.
\end{abstract}

\footnotetext{
Departments of Medicine and Clinical Biochemistry, Christchurch Hospital, Christchurch, New Zealand

J L O'DONNELL, MB, CHB, medical registrar

J R SHARMAN, BSC, toxicologist

E J BEGG, FRACP, clinical pharmacologist

B M COLLS, FRACP, FRCP, consultant physician

PW MOLLER, FRCP, FRACP, rheumatologist

Correspondence to: Dr Begg, department of medicine.
}

\section{Introduction}

Mianserin is a tetracyclic antidepressant which has occasionally caused severe blood dyscrasias.' Pharmacokinetic studies of the drug in 14 elderly patients showed a terminal elimination half life of $27 \cdot 0$ (SD 13.1) hours, while in eight healthy adults it was $9 \cdot 6(1.9)$ hours. ${ }^{2}$ Saturable elimination kinetics-as seen, for example, with phenytoin-has been said not to occur with mianserin. ${ }^{3}$ We report two cases of mianserin induced neutropenia associated with prolonged elimination of the plasma concentrations, which declined in a manner suggesting that the metabolising enzymes were saturated.

\section{Case 1}

A 60 year old woman was found to be neutropenic $\left(0.034 \times 10^{9} / 1 ;\right.$ normal range $\left.2 \cdot 0-8 \cdot 0 \times 10^{9} / \mathrm{l}\right)$ when she presented with a febrile illness due to right otitis externa. She had been prescribed mianserin $30 \mathrm{mg}$ daily six weeks before instead of her usual amitriptyline. Other medications included labetalol $100 \mathrm{mg}$ twice daily and hydrochlorothiazide $50 \mathrm{mg}$ and amiloride 5 $\mathrm{mg}$ daily. Liver function values were mildly abnormal.

The plasma mianserin concentration was high initially and declined only slowly when the drug was withdrawn. This is shown in the figure along with the serial neutrophil counts. The initial slope of the mianserin elimination curve showed a half life of about 6.5 days. The terminal elimination half life was roughly 23 hours. 